\title{
Surface morphologies and erosion rates of metallic building materials after sandblasting
}

\author{
C.-K. Fang ${ }^{a, *}$, T.H. Chuang ${ }^{b}$ \\ ${ }^{a}$ Department of Mechanical Engineering, China Institute of Technology and Commerce, 245 Yen-Chu-Yuan Rd., Sec. 3, Nankang, Taipei 115, Taiwan \\ ${ }^{\mathrm{b}}$ Institute of Materials Science and Engineering, National Taiwan University, Taipei 106, Taiwan
}

Received 13 July 1998; received in revised form 22 December 1998; accepted 26 January 1999

\begin{abstract}
Erosion behaviors of AISI 430 and 304 stainless steels, ARC-TEN weathering steel, brass, and 6063 aluminum alloy were experimentally investigated using a sandblasting type test rig and silicon carbide erodent particles. Surface morphologies of eroded specimens were examined using scanning electron microscopy. The volume loss was measured for the evaluation of erosion rates. This paper stresses the relationship between erosion rate and surface hardness (before and after erosion). It was found that the erosion rate is proportional to $(\mathrm{Hv})^{-n}$, where $\mathrm{Hv}$ is the microhardness number after erosion testing, and the exponent $n$ is 1.4 or 3 , depending on conditions. (C) 1999 Elsevier Science S.A. All rights reserved.
\end{abstract}

Keywords: Erosion; Sandblasting; Metallic materials; Surface hardness

\section{Introduction}

Metals and alloys are extensively used as building materials. The degradation of these materials might cause color fading or structural damage, particularly in outdoor or harsh environments. The synergy of wind and sand may result in eventual erosion of the building materials.

In the selection of building materials, one needs to consider whether the material is to be exposed to an erosive environment. However, a harder material is not necessarily more resistant to erosion. In 1967, Finnie [1] showed some correlation between erosion rate and hardness of pure metals. In 1968, Patel [2] made a comprehensive study on the effect of surface hardness on the erosion of metals. The relationship between surface hardness and erosion damage was then studied by other researchers [3-6] in the 1970s. Finnie's [5,7] cutting or micromachining model predicts an inverse relationship between the erosion rate and the hardness of the target material. According to actual experimental data [8-13], such a relationship is only valid for annealed pure metals, but not for alloys. It was reported that any increase in hardness achieved by heat treatment, cold work, or by precipitation

\footnotetext{
* Corresponding author
}

has no effect on erosion resistance [5,7], with the exception of precipitation hardened 6061 aluminum (Al) alloy [14].

It was observed, however, that the erosion rate of plain carbon steel increases with an increase in hardness through microstructural modifications [15]. Under normal impact conditions, Sundararajan and Shewmon's [16] localization model predicted the insensitivity of the erosion rate to the hardness of a metal or alloy. Several other observations $[17,18]$ also indicated that erosion rates are independent of material hardness. Oka et al. [19] postulated that good correlations were recognized only for pure metals or alloys with the same composition system.

In general, it is accepted that hardness is a good predictor of erosion for pure metals with the exception of materials with partial covalent bonding such as Mo and W. On the other hand, the dependence of erosion resistance on hardness in alloys is minimal or nearly non-existent. The reasons can be many. Hutchings [20] postulated that the critical strain to fracture of the target material needs to be considered as well. He proposed a model showing that erosion resistance is proportional to $H^{1.5} e^{2}$, where $H$ is the dynamic hardness of a material and $e$ is the critical strain to fracture. In their study of WC and TiC-base hard metals, Reshetnyak and Kuybarsepp [21] found that the difference in wear resistance between hard metals with 
Table 1

Chemical compositions of the tested materials

\begin{tabular}{|c|c|c|c|c|c|c|c|c|c|c|c|c|}
\hline & $\mathrm{C}$ & $\mathrm{Si}$ & $\mathrm{Mn}$ & $\mathrm{P}$ & $\mathrm{S}$ & $\mathrm{Cu}$ & $\mathrm{Ni}$ & $\mathrm{Cr}$ & $\mathrm{Mg}$ & $\mathrm{Fe}$ & $\mathrm{Al}$ & $\mathrm{Zn}$ \\
\hline AISI 430 & 0.11 & 0.89 & 0.88 & 0.04 & 0.02 & - & - & 17.85 & - & bal. & - & - \\
\hline AISI 304 & 0.08 & 0.94 & 1.22 & 0.04 & 0.02 & - & 8.41 & 18.14 & - & bal. & - & - \\
\hline ARC-TEN & 0.12 & 0.42 & 0.45 & 0.09 & 0.02 & 0.46 & 0.85 & 0.61 & - & bal. & - & - \\
\hline $6063 \mathrm{Al}$ & - & 0.45 & 0.07 & - & - & 0.08 & - & 0.06 & 0.75 & 0.29 & bal. & - \\
\hline
\end{tabular}

ARC-TEN weathering steel was supplied by China Steel, Kaoshiung, Taiwan.

equal hardness levels can be attributed to differences in their resistance to fracture. They stated that resistance to erosive wear depends on the hardness and compressive strength of the material. Hutchings [22] indicated that the relationship between erosion rate and hardness depends on the erodent properties and erosion-test conditions. Some observations indicated that erosion rates depend on the ratio of particle to target hardness [23]. Recently, Levin et al. [24] found that the erosion rates of weld overly coatings are not related to hardness but the measured area under the microhardness profile curve. On the other hand, some investigators [25-28] found that erosion tends to increase with an increase in hardness or tensile strength and decreases somewhat with the improvement in ductility. Consequently, the relationship between hardness and erosion resistance needs to be clarified.

Oka et al. [19] found that the relationship between erosion rate and material hardness was improved remarkably by measuring the surface hardness after the erosion test, instead of measuring the initial hardness. The surface hardness of the eroded specimen with respect to work hardening and softening was reasonably correlated with erosion damage. They also found an increase in hardness of the fully eroded surface of iron and $\mathrm{Al}$, but a decrease for quenched carbon tool steel. Recently, Oka et al. [29] found that the maximum erosion damage and the shape of damage curves shifted monotonically according to the material (initial) hardness. They derived a semi-theoretical equation in which the erosion rate is a trigonometric function of both impact angle and material hardness. Whether the erosion rate is more related to hardness before or after erosion is a matter of argument. In reality, the erosion rate might be more related to the hardness of the target material during the erosion test instead of that before or after the test. However, direct measurement of the hardness during the test is difficult.

Table 2

Mechanical properties of the tested materials

\begin{tabular}{llll}
\hline & $\sigma_{y}\left(\mathrm{~N} / \mathrm{mm}^{2}\right)$ & $\mathrm{UTS}\left(\mathrm{N} / \mathrm{mm}^{2}\right)$ & Elongation $(\%)$ \\
\hline AISI 430 & 310 & 538 & 32 \\
AISI 304 & 241 & 586 & 55 \\
ARC-TEN & 380 & 491 & 25 \\
Brass & 414 & 352 & 28 \\
$6063 \mathrm{Al}$ & 214 & 248 & 12
\end{tabular}

The objective of the present paper is to study the solid-particle erosion for different materials, including AISI 430 and 304 stainless steels (SS), ARC-TEN weathering steel, brass, and $6063 \mathrm{Al}$ alloy. For comparison, volume loss was used instead of weight loss because of the different densities in the various materials. The relationship between erosion rate and surface hardness measured before and after sandblasting were also evaluated. In addition, eroded surfaces were examined using scanning electron microscopy.

\section{Experimental}

Based on the American Standard ASTM G76, a sandblast type test rig with a gas jet was employed in the erosion tests. The set-up consists of a particle-gas supply
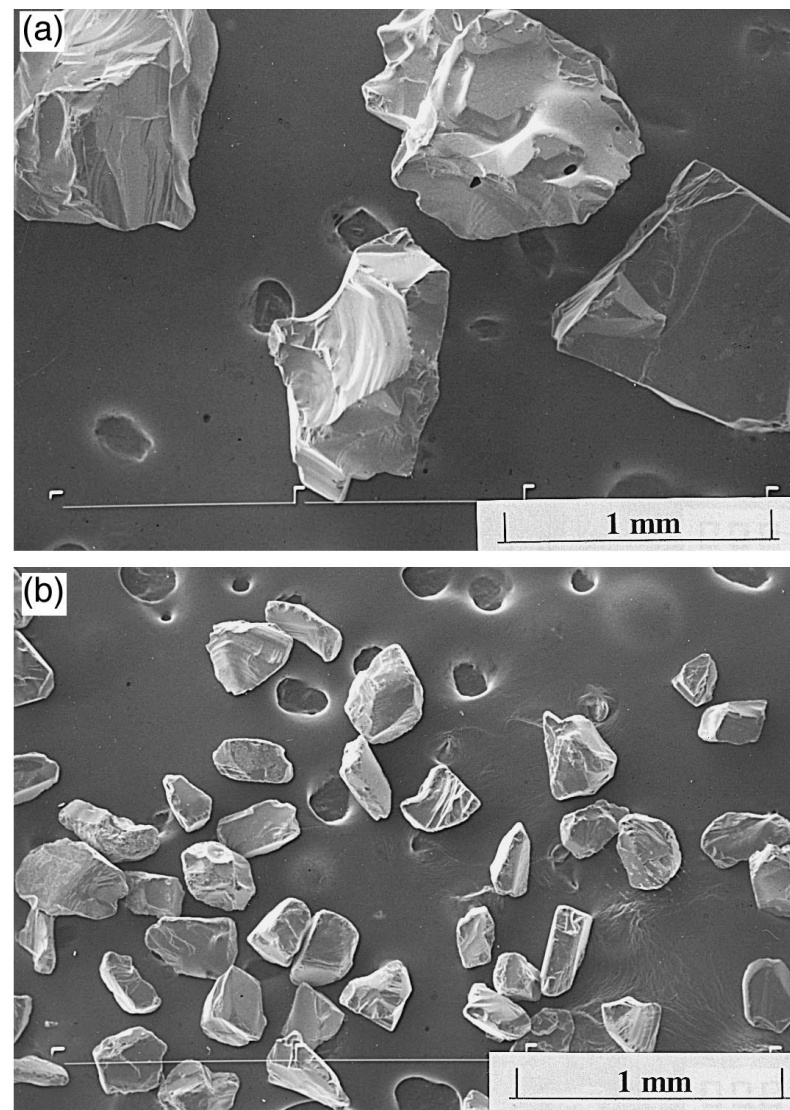

Fig. 1. Scanning electron micrographs of abrasive particles of grit sizes (a) 24 and (b) 80 . 
Table 3

Densities of the tested materials

\begin{tabular}{llllll}
\hline Materials & $430 \mathrm{SS}$ & $304 \mathrm{SS}$ & ARC-TEN & Brass & $6063 \mathrm{Al}$ \\
\hline Densities $\left(\mathrm{g} / \mathrm{cm}^{3}\right)$ & 7.433 & 7.425 & 7.789 & 8.449 & 2.707
\end{tabular}

system, an exit nozzle, and a chamber. The chamber enables specimens to be studied under well-controlled exposure conditions. Compressed air with a pressure of 60 psi was used to accelerate abrasive particles. The air was mixed with abrasive particles from the reservoir and then flowed into the nozzle. The flow rate could be controlled in the range of $10-1001 / \mathrm{min}$. The working distance (between the specimen and nozzle tube) was $20 \mathrm{~mm}$. The samples were angularly fixed from $15^{\circ}$ to $90^{\circ}$, at every $15^{\circ}$ pitch.

Five target materials were used in the experiments: AISI 430 and 304 SS, ARC-TEN weathering steel, brass $(\mathrm{Cu}-30 \% \mathrm{Zn})$, and $6063 \mathrm{Al}$ alloy. Erosion specimens were cut from commercial grade plates. The chemical compositions and mechanical properties of these alloys are shown in Tables 1 and 2, respectively. The $6063 \mathrm{Al}$ alloy was hot-rolled at $450^{\circ} \mathrm{C}$ and subsequently aged with $\mathrm{T} 6$ treatment. The as-received surface was directly employed for testing after ultrasonic rinsing in acetone. The surface hardness of each material was measured before and after erosion using a Micro-Vickers hardness tester with an indentor load of $300 \mathrm{~g}$, which lasted for $15 \mathrm{~s}$. After weighing, each specimen was conditioned in the constant temperature-constant humidity chamber for $24 \mathrm{~h}$ prior to testing.

Erosion tests were performed at room temperature and $80 \%$ relative humidity. Silicon carbide $(\mathrm{SiC})$ abrasive particles of grit size 24 and 80 were employed as the erodent material. Fig. 1 illustrates the contours of the particles in the scanning electron micrograph. In each test, the specimen was exposed to a total of $2.5 \mathrm{~kg}$ abrasive in $12 \mathrm{~min}$ for $\mathrm{SiC} 24$, or $15 \mathrm{~min}$ for $\mathrm{SiC} 80$. The particle impact velocities were 25 and $30 \mathrm{~m} / \mathrm{s}$ for the particles of grit sizes 24 and 80, respectively. After sandblasting, each specimen was brushed off lightly, and weighed to determine the weight loss due to erosion, which was then converted to volume loss through dividing the weight loss by the density of each material. The densities of the tested materials are listed in Table 3. Three samples have been made using one parameter set for averaging. The standard deviations are less than $5 \%$.

\section{Results and discussion}

\subsection{Surface morphologies}

Erosion patterns were examined using a scanning electron microscope to characterize the morphology and the mode of material removal. The typical SEM micrographs of the eroded surfaces after sandblasting for $430 \mathrm{SS}, 304$ SS, ARC-TEN weathering steel, brass and $6063 \mathrm{Al}$ alloy are presented in Figs. 2-6, respectively. Silicone carbide particles of grit size 24 were employed as the erodent
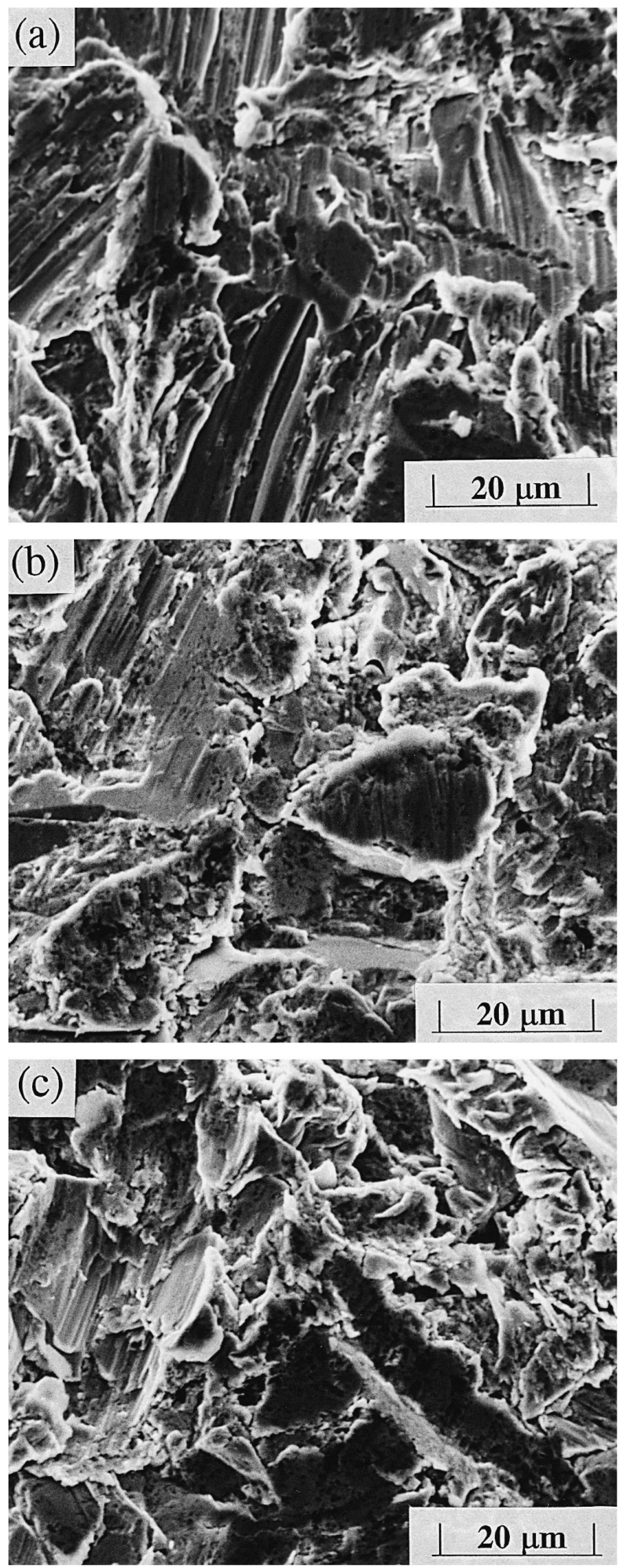

Fig. 2. Surface morphologies of $430 \mathrm{SS}$ eroded by $\mathrm{SiC}$ particles at (a) $15^{\circ}$, (b) $45^{\circ}$, and (c) $90^{\circ}$ attack angles. 

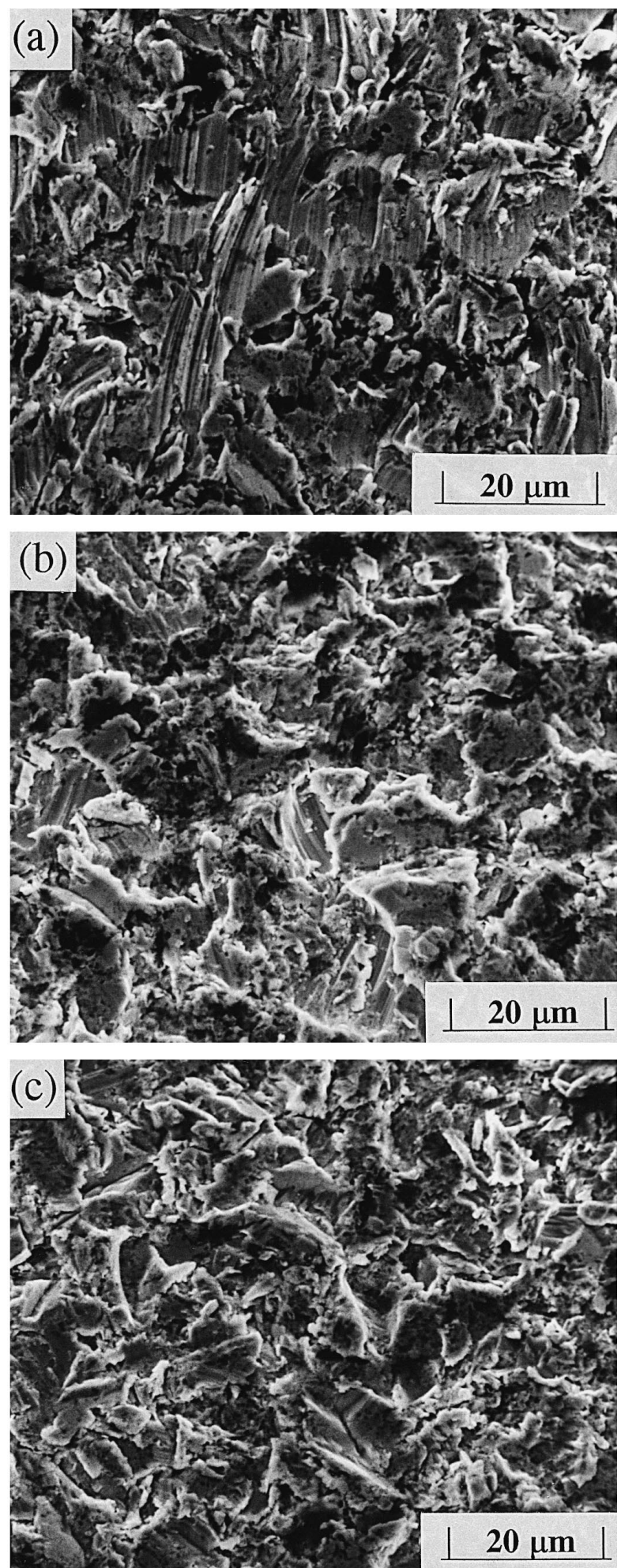

Fig. 3. Surface morphologies of $304 \mathrm{SS}$ eroded by $\mathrm{SiC}$ particles at (a) $15^{\circ}$, (b) $45^{\circ}$, and (c) $90^{\circ}$ attack angles.

material. The results for $15^{\circ}, 45^{\circ}$, and $90^{\circ}$ attack angles for each material are illustrated. The direction of particle motion during sandblasting is from bottom to top on the micrographs.
Fig. 2 illustrates the surface morphologies of AISI 430 SS at different attack angles. Fig. 2(a) shows the results for a $15^{\circ}$ attack angle. It was observed that microcutting tracks cover the entire eroded area. While comparing the mor-
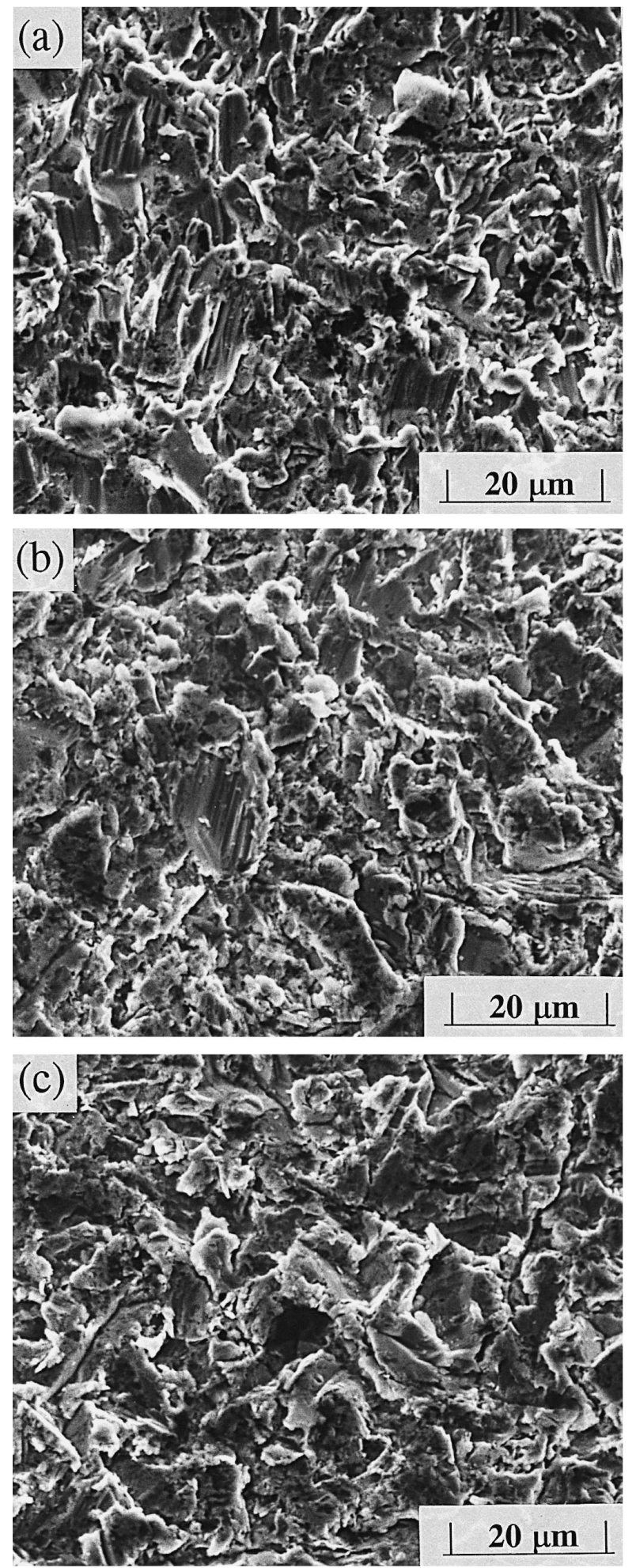

Fig. 4. Surface morphologies of ARC-TEN weathering steel eroded by $\mathrm{SiC}$ particles at (a) $15^{\circ}$, (b) $45^{\circ}$, and (c) $90^{\circ}$ attack angles. 

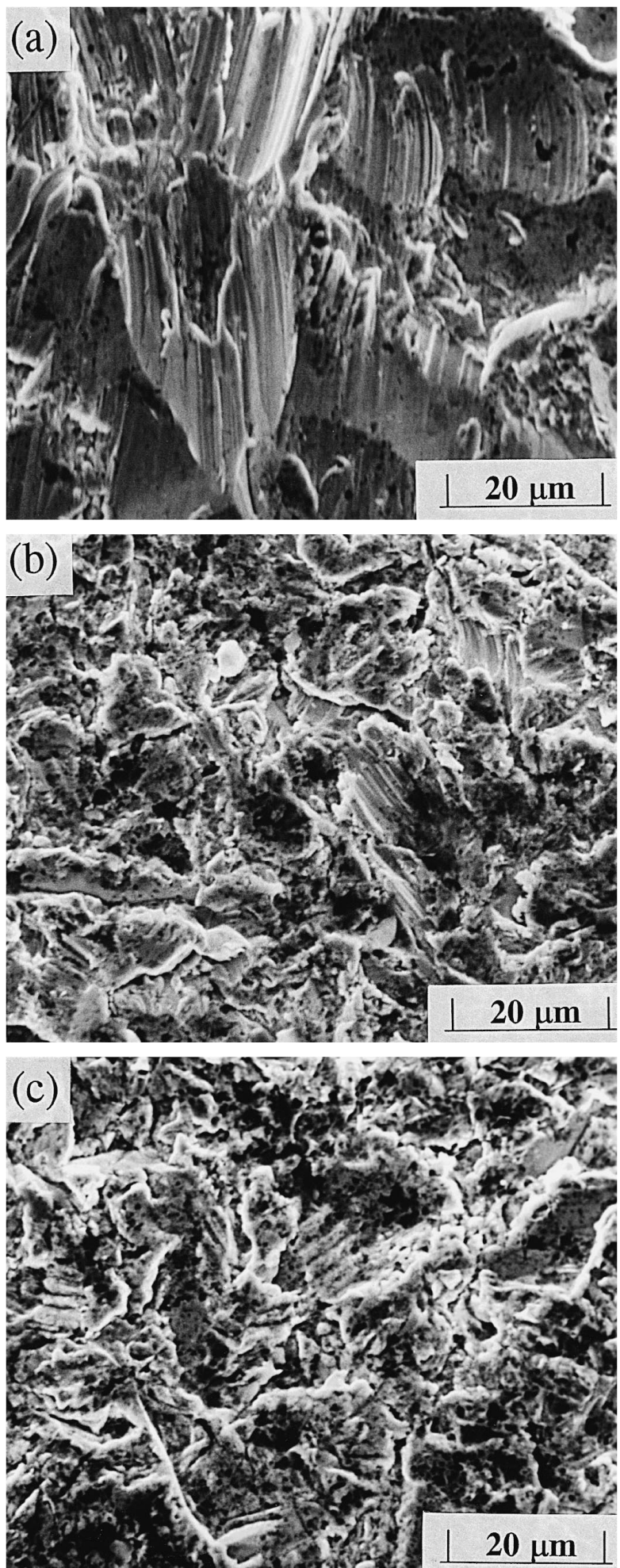

Fig. 5. Surface morphologies of brass eroded by $\mathrm{SiC}$ particles at (a) $15^{\circ}$, (b) $45^{\circ}$, and (c) $90^{\circ}$ attack angles.

phologies for different attack angles, it was found that the total area and the individual size of the gouged region decreases with an increase in attack angle.

Fig. 3 shows the microdamage of AISI 304 SS eroded at different attack angles. Compared with the surface mor- phologies of 430 SS (Fig. 2), 304 SS has fewer and smaller microcutting tracks, although they are of about the same surface hardness $(\mathrm{Hv}=185)$ before testing. The hardness numbers after erosion tests are 270 and 282 for 430 and 304 SS, respectively. The higher hardness number
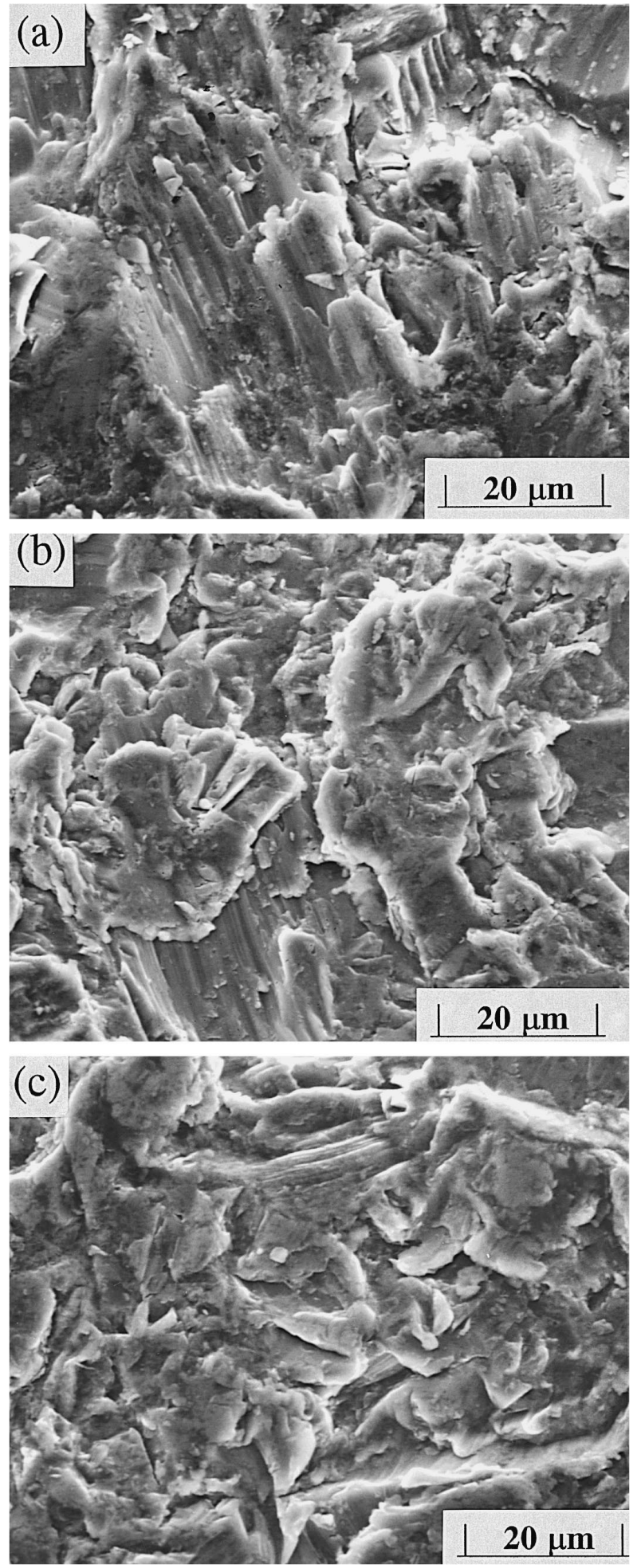

Fig. 6. Surface morphologies of 6063 aluminum alloy eroded by $\mathrm{SiC}$ particles at (a) $15^{\circ}$, (b) $45^{\circ}$, and (c) $90^{\circ}$ attack angles. 


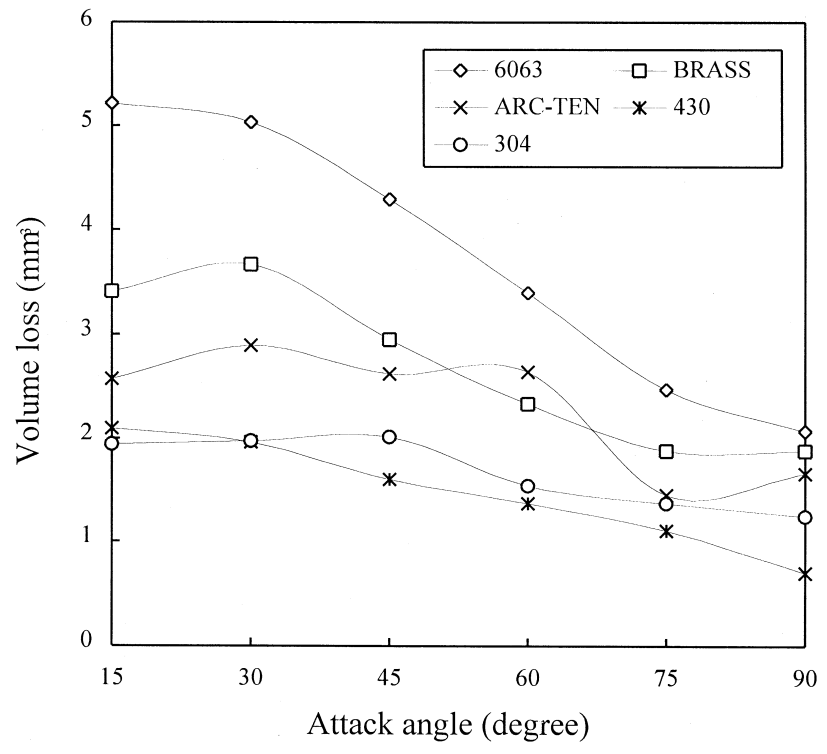

Fig. 7. Volume loss vs. attack angle for five materials.

of 304 SS after erosion might be related to the workhardening of the eroded surface. It is observed that cutting tracks cover the entire eroded area for a $15^{\circ}$ attack angle, while very rare cutting tracks appear at higher attack angles. Almost no microcutting tracks can be found in frontal impact, as shown in Fig. 3(c). The observation seems to support the two-mechanism viewpoint $[3,5,16,35-37]$, i.e., the overall erosion behavior can be determined by a superposition of micromachining and damage-accumulation. The former dominates at low attack angles while damage-accumulation dominates at normal impact.

Morrison et al. [38], however, postulated the singlemechanism viewpoint based on their study on erosion of 304 SS. They found similar overall features at low and high angles of impact, i.e., the erosion mechanism is independent of attack angle. This may be due to the fact that their SEM micrographs were only taken for $20^{\circ}$ and $90^{\circ}$ attack angles. If lower attack angles had been investigated in their study, microcutting tracks might have been observed, similar to our observation at $15^{\circ}$ attack angle as shown in Fig. 3(a). Our observations support Magnee's [39] and Wilson and Ball's [41] recent argument that the normal component of the particle motion leads to deformation and strain hardening of the target, whereas that tangential to the target had a cutting and ploughing effect.

The surface morphologies of ARC-TEN weathering steel are illustrated in Fig. 4. Many relatively small microcutting tracks are observed for the $15^{\circ}$ attack angle.

Fig. 5 illustrates the erosive microdamage of brass. Since $\mathrm{Cu}-30 \%$ brass is relatively soft, extensive and relatively large microcutting tracks are observed for the $15^{\circ}$ attack angle. However, the amount of microcutting tracks decreases significantly with the increase in attack angle for attack angles larger than $15^{\circ}$, and nearly none were observed for high attack angles.
Fig. 6 shows the micrographs for $6063 \mathrm{Al}$ alloy. Extensive ploughing and the resulting lip formation are evident in the micrograph for the $15^{\circ}$ attack angle, as indicated in Fig. 6(a). Considerable surface deformation due to the striking of the particle corners is observed. The particles gouged the surface and pushed up ridges of material in front of them. Some of these ridges were eroded during subsequent collisions. Microcracking and chipping events were noticed for frontal impact, as shown in Fig. 6(c), whereas plastic flow was very limited. It was observed that the amount of microploughing decreases with the increase of attack angle. Detailed discussion can be seen in the authors' earlier work [30].

In general, microcutting or pile-up leading to flake formation and separation is observed. Lip formation is observed for low attack angles, while brittle fracturing showing microcracking and chipping events with limited plastic flows occurs for high attack angles. On subsequent impacts, the displaced material seems to be either cut or flattened into a platelet, depending on whether the particle is impacting on the edge or its face, as indicated by Yerramareddy and Bahadur [31]. The amount of microcutting tracks decreases with an increase in attack angle. Flake formation is observed at all attack angles, whereas the gouged marks resulting from the sliding of the erodent against the target are absent for frontal impacts, and craters are observed instead.

\subsection{Volume loss}

Fig. 7 illustrates the test results for volume loss of the five materials at room temperature and at $80 \%$ relative humidity. $\mathrm{SiC}$ abrasive particles of grit size 24 were employed as the erodent material. In general, the maximum volume loss occurs at low attack angles. For most of the attack angles, the sequence for the amount of volume

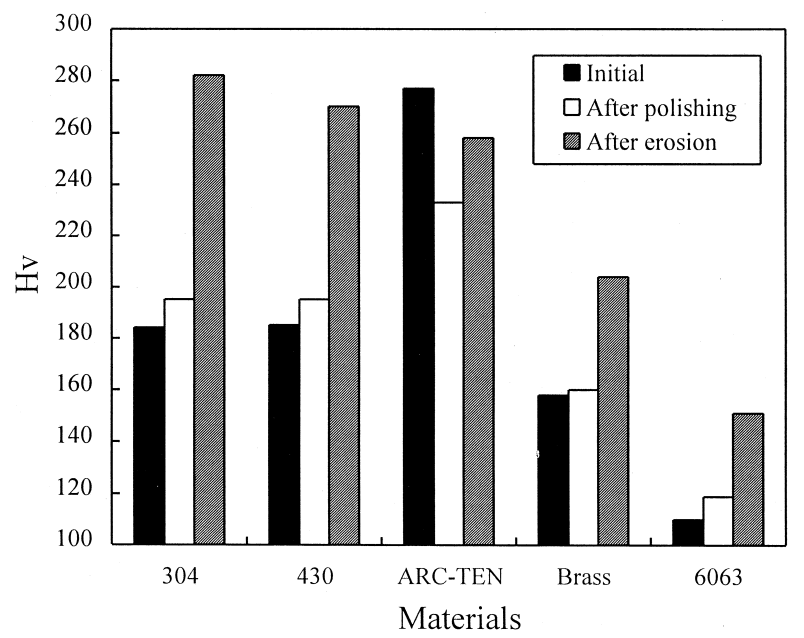

Fig. 8. Hardness numbers before testing, after polishing, and after erosion testing. 


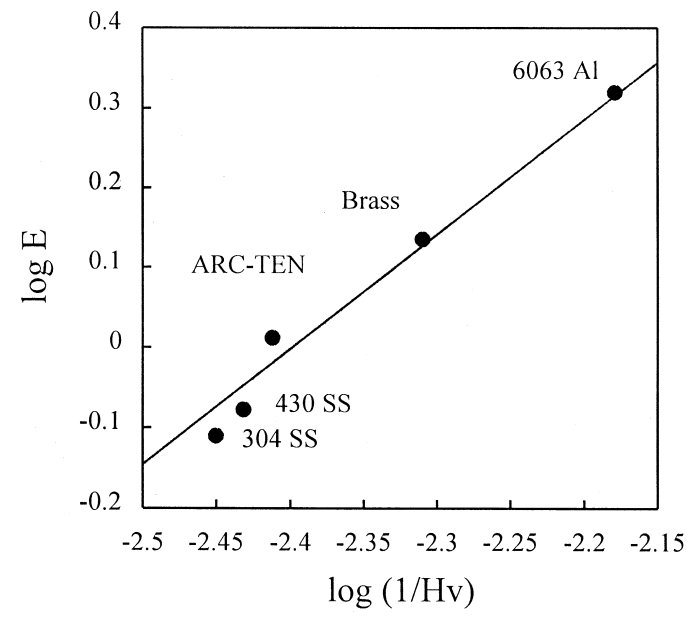

Fig. 9. Relationship between erosion rate and reciprocal hardness number after erosion testing for different materials eroded by 24 grit $\mathrm{SiC}$ particles at $15^{\circ}$ attack angle.

loss is: SS $<$ ARC-TEN weathering steel $<$ brass $<6063$ $\mathrm{Al}$ alloy. The peak attack angles for volume loss are in accordance with generally accepted erosion behavior, namely, that maximum erosion occurs at a low attack angle for ductile materials [1,32]. The results for $304 \mathrm{SS}$ are also consistent with the observation of Singh et al. [33], in which the maximum erosion rate occurs at a low attack angle. It is observed that 304 SS has more volume loss than $430 \mathrm{SS}$ at attack angles larger than $30^{\circ}$, with less volume loss at grazing attack angles.

\subsection{Effects of surface hardness}

Conventionally, surface hardness before testing was used to predict the erosion resistance of a material. However, surface hardness varies due to work hardening and softening by erosion. Consequently, the surface hardness during and after erosion might be more related to erosion resistance. The hardness numbers before and after erosion tests at the $15^{\circ}$ attack angle are illustrated in Fig. 8. Silicone carbide particles of grit size 24 were employed as the erodent material. According to Fig. 7, the sequence for the amount of volume loss is: $304 \mathrm{SS}<430 \mathrm{SS}<\mathrm{ARC}$ TEN weathering steel $<$ brass $<6063 \mathrm{Al}$ alloy. The values of $1 / \mathrm{Hv}$ after erosion have the same sequence, while those before erosion do not. Consequently, the surface hardness after erosion is more related to the volume loss than that before testing. This is consistent with Oka's observation [19]. Compared with the initial hardness shown in Fig. 8, it is observed that the surface hardness of ARC-TEN weathering steel is reduced after testing, whereas that of the other four materials is increased due to work hardening. This is because ARC-TEN weathering steel had an oxide film on the surface before testing, which subsequently eroded during the test, exposing the softer base material.

To examine the hardness of the base material, the surface film was removed by polishing the specimen with emery paper in discrete steps down to a 600 grade finish. The results are also illustrated in Fig. 8. Compared with the initial value, the surface hardness for ARC-TEN steel is significantly reduced after polishing, while those for the other four materials are only slightly increased. Comparing the results for surface hardness after polishing and after the erosion test, as shown in Fig. 8, it is observed that surface hardening occurred in each material after the erosion test was performed. In particular, the hardness of the 304 and 430 SS are significantly increased after erosion.

In quasistatic indentation, the diameter of the indentation is proportional to $\mathrm{Hv}^{-0.5}$. Oka et al. [19] postulated that if the material removal caused by the impact of solid particles follows the fractional loss of the volume of the indentation, the same relationship can be obtained. He stated that the relationship between erosion rate $E$ (volume loss per kilogram of abrasive, expressed in units of $\mathrm{mm}^{3} / \mathrm{kg}$ ) and surface hardness $\mathrm{Hv}$ (after erosion) can be

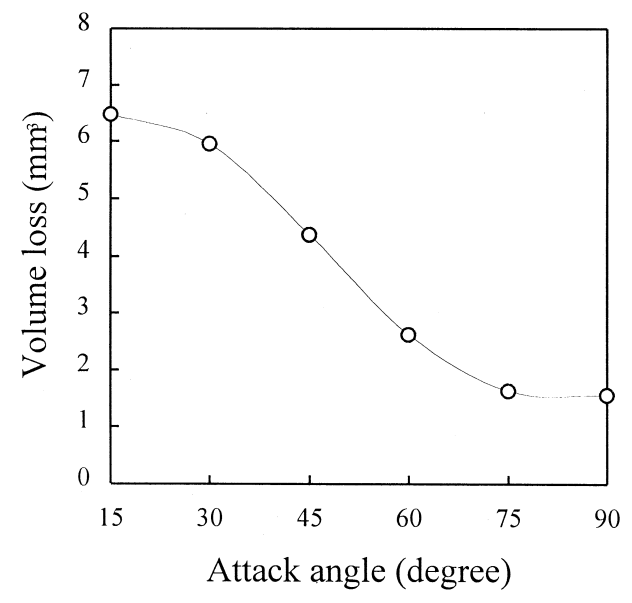

(a)

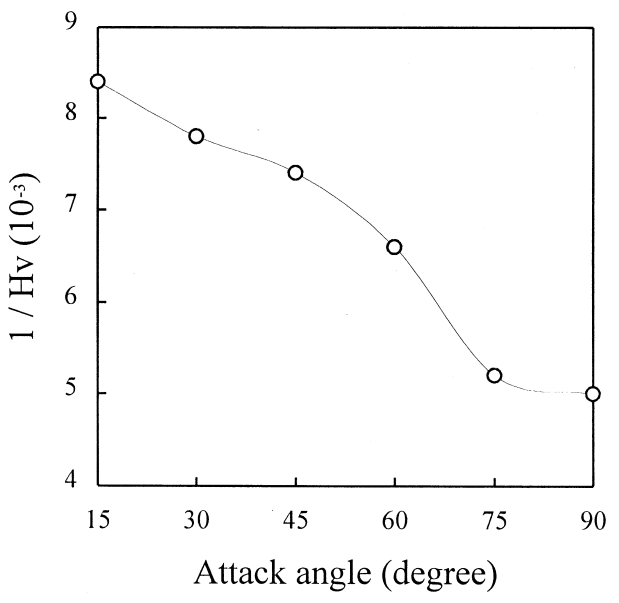

(b)

Fig. 10. Volume loss and reciprocal surface hardness number of $6063 \mathrm{Al}$ alloy after erosion testing at different attack angles. 


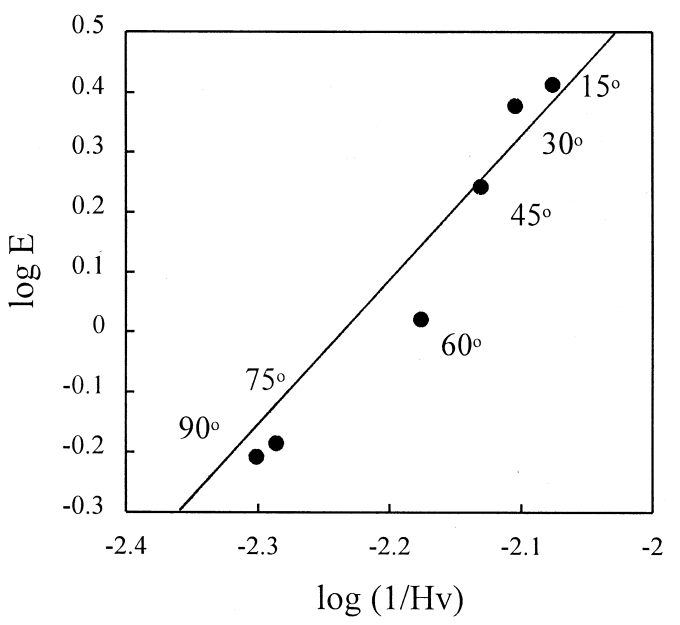

Fig. 11. Relationship between erosion rate and reciprocal hardness number after erosion testing for $6063 \mathrm{Al}$ alloy eroded by 80 grit $\mathrm{SiC}$ particles at different attack angles.

expressed as $E=K(\mathrm{Hv})^{-n}$, where $K$ and $n$ are constants. Employing the data of the five materials, the relationship between $\log E$ and $\log \left(\mathrm{Hv}^{-1}\right)$ is shown in Fig. 9. We obtain the slope $n=1.4$, which is twice as large as Oka's result, but very close to Hutching's [20]. The deviation in the value of $n$ might be due to the differences in the experimental conditions, viz. particle size and impact velocity.

It would be interesting to study the attack angle effect on work hardening and erosion. However, the eroded surfaces for attack angles larger than $15^{\circ}$ were too rough for the Micro-Vickers hardness measurement if 24 grit erodent was used. In order to facilitate the surface hardness testing, the surface can be smoothened by a very light chemical polishing [2], or using finer particles. Finer $\mathrm{SiC}$ particles of grit size 80 were employed in the present erosion tests of $6063 \mathrm{Al}$ alloy. Fig. 10(a) and (b) show the volume loss vs. attack angle and the reciprocal hardness number vs. attack angle, respectively. The similar shape of these two curves indicates that the higher attack angle might result in more work hardening, and thus, less volume loss due to erosion.

One might suspect that the increases of hardness at large angles was due to particle entrapment in the surface layer as indicated by Wilson and Ball [41]. They found that the $\mathrm{SiC}$ erodent fragments, which were embedded into the Al 6061 alloy, added to the surface hardness and resulted in increased erosion resistance at $90^{\circ}$ erosion. Embedded particles were, however, not found in the SEM micrographs in the present study. As a result, the increased surface hardness was probably due to the work hardening caused by plastic deformation. According to Magnee's argument [39] that the normal component of the particle motion leads to deformation of the target, the degree of deformation or work hardening is expected to increase with the increasing attack angle. The relationship between erosion rate and reciprocal hardness numbers after the erosion test for $6063 \mathrm{Al}$ alloy is illustrated in Fig. 11. Similar to Fig. 9, the increase in hardness is accompanied by an increase in erosion resistance. The same trend was observed in the research of Salik et al. [40] on a precipitation hardened $6061 \mathrm{Al}$ alloy, similar to the material examined in the present work. As illustrated in Fig. 11, a linear relationship is observed in the logarithmic scale, with a slope $n=3$.

It should be noted that erosion involves the material deformation under high strain rate, and the hardness of the material under erosion conditions is generally different from that obtained from the static hardness test [34]. The effect of material flow behavior on erosion would be an interesting future study.

\section{Conclusions}

(1) In general, ploughing or pile-up leading to flake formation and separation, and lip formation is observed for low attack angles, while brittle fracture showing microcracking and chipping events with limited plastic flows occurs for high attack angles. The total area and the individual size of the gouged region decrease with the increase in attack angle.

(2) Although 304 and $430 \mathrm{SS}$ are of about the same surface hardness before erosion, the former has fewer and smaller microcutting tracks.

(3) In most of the attack angles, the sequence for the amount of volume loss is: SS $<$ ARC-TEN weathering steel $<$ brass $<6063$ Al alloy. AISI 304 SS has more volume loss than $430 \mathrm{SS}$ at attack angles larger than $30^{\circ}$, with less volume loss at grazing attack angles.

(4) The surface hardness after the erosion test is more related to the volume loss than it is before testing.

(5) The relationship between erosion rate $E$ (volume loss per kilogram of abrasive) and surface hardness $\mathrm{Hv}$ (after erosion) can be expressed as $E=K(\mathrm{Hv})^{-n}$, where $K$ is a constant. The index number $n$ is 1.4 or 3 depending on conditions.

\section{References}

[1] I. Finnie, J. Wolak, Y. Kabil, J. Mater. 2 (1967) 682-700.

[2] D. Patel, Master of Science Thesis, Washington State University, 1968.

[3] I. Finnie, Wear 19 (1972) 81-90.

[4] G.L. Sheldon, A. Kanhere, Wear 21 (1972) 195-209.

[5] I. Finnie, D.H. McFadden, Wear 48 (1978) 181.

[6] G.L. Sheldon, Trans. ASME, J. Eng. Mater. Tech., 1977, pp. 133-137.

[7] I. Finnie, Proc. 3rd US Natl. Congr. of Applied Mechanics, ASME, New York, USA, 1985, pp. 527-532.

[8] A.W. Ruff, S.M. Wiederhorn, Treatise on Materials Science and Technology, Academic Press, New York, Vol. 16, 1979, pp. 69-126.

[9] I.M. Hutchings, Proc. Conf. on Corrosion/Erosion of Coal Conversion System Materials, NACE, Houston, 1979, p. 393. 
[10] P.G. Shewmon, G. Sundararajan, Annu. Rev. Mater. Sci. 13 (1983) 303.

[11] G. Sundararajan, Trans. Indian Inst. Met. 36 (1986) 474.

[12] T. Foley, A. Levy, Wear 91 (1983) 45.

[13] T. Foley, A. Levy, Wear of Materials, ASME, New York, 1983, pp. 346-353.

[14] J. Salik, D. Buckley, W.A. Brainard, Wear 65 (1981) 351-358.

[15] A. Levy, D. Jahamir, in: K. Natesan (Ed.), Corrosion-Erosion Behavior of Materials, Metallurgical Society of AIME, New York, 1980, p. 177.

[16] G. Sundararajan, P.G. Shewmon, Wear 84 (1983) 237.

[17] A.V. Levy, Solid Particle Erosion and Erosion-Corrosion of Metals, ASM International, Materials Park, OH, 1995, p. 43.

[18] B.F. Levin, J.N. Dunpont, A.R. Marder, Wear 181-183 (1995) 810.

[19] Y.I. Oka, M. Matsumura, T. Kawabata, Wear 162-164 (1993) 688-695.

[20] I.M. Hutchings, Wear 70 (1981) 269.

[21] H. Reshetnyak, J. Kuybarsepp, Wear 177 (1994) 185-193.

[22] I.M. Hutchings, J. Appl. Phys. 25 (1986) A212.

[23] P.H. Shipway, I.M. Hutchings, Wear 193 (1996) 105-113.

[24] B.F. Levin, J.N. Dupont, A.R. Marder, J. Mater. Sci. 33 (1998) 2153-2163.
[25] L. Ambrosini, S. Bahadur, Wear 117 (1987) 37-48.

[26] M. Naim, S. Bahadur, Wear 112 (1986) 217-234.

[27] M. Naim, S. Bahadur, Wear 128 (1988) 239-247.

[28] M. Naim, S. Bahadur, Lub. Eng. 46 (1990) 53-57.

[29] Y.I. Oka, H. Ohnogi, T. Hosokawa, M. Matsumura, Wear 203-204 (1997) 573-579.

[30] C.-K. Fang, T.H. Chuang, submitted for publication, 1997.

[31] S. Yerramareddy, S. Bahadur, Wear 142 (1991) 253-263.

[32] G. Grant, W. Tabakoff, J. Aircraft 12 (1975) 471-478.

[33] T. Singh, S.N. Tiwari, G. Sundararajan, Wear 145 (1991) 77-100.

[34] G. Sundararajan, Wear 186-187 (1995) 129-144.

[35] I.M. Hutchings, R.E. Winter, J.E. Field, Proc. R. Soc. London, Ser. A 348 (1976) 379.

[36] I.M. Hutchings, Wear 70 (1981) 269.

[37] R. Bellman Jr., A. Levy, Wear 70 (1981) 1.

[38] C.T. Morrison, R.O. Scattergood, J.L. Routbort, Wear 111 (1986) $1-13$.

[39] A. Magnee, Wear 181-183 (1995) 500-510.

[40] J. Salik, D. Buckley, W.A. Brainard, Wear 65 (1981) 351-358.

[41] S. Wilson, A. Ball, in: Friedrich (Ed.), Advances in Composite Tribology, Elsevier, 1993, pp. 311-366. 